\title{
The Dynamic Analysis of Municipal Pipeline Under Shield Tunneling Construction Based on the ABAQUS Software
}

\author{
Ren Yanrong, Chen Peipei* \\ Email address: \\ Chenpeipei@bucea.edu.cn (Chen Peipei) \\ ${ }^{*}$ Corresponding author
}

Science school, Beijing University of Civil Engineering and Architecture, Beijing, China

\section{To cite this article:}

Ren Yanrong, Chen Peipei. The Dynamic Analysis of Municipal Pipeline Under Shield Tunneling Construction Based on the ABAQUS Software. Journal of Civil, Construction and Environmental Engineering. Vol. 4, No. 6, 2019, pp. 94-99. doi: 10.11648/j.jccee.20190406.11

Received: July 6, 2019; Accepted: October 9, 2019; Published: December 16, 2019

\begin{abstract}
Shield tunneling construction is the modern popular used model in underground pipelines. In this paper, finite numerical method based on ABAQUS software has been used to simulate the effect of shied tunneling construction on the underground pipelines, the effect between the pipeline and soil interface had been considered, the dynamic effect and response have been simulated for underground pipelines. Numerical results show that the tunnel depth, propelling force, pipe's diameter and pipe's depth have greater influence on the pipeline's displacement. The rules and conclusions drawn in the paper can provide reference for the pipeline protection in similar projects in the future.
\end{abstract}

Keywords: Shield Tunneling Construction, Municipal Pipelines, Dynamic Analysis, ABAQUS Software

\section{Introduction}

When building the subway, shield tunneling had been used. Shield tunneling is one of the widely used technologies in metro tunnel construction [1]. The shield tunneling will cause the soil around tunnel to deform, and lead to the underground pipeline to cause bigger additional deformation and stress, and also cause the underground pipeline to destroy. So, we should assure the safety of all kinds of pipelines. The calculation methods of underground pipelines stress mainly include theoretical calculation method, numerical simulation method and model experiment methods. [2]

The beneficial conclusions had been obtained from documents [3-16] that described the affects of shield tunneling to underground pipelines from different point of view. The numerical simulation had been carried on the affects of shield tunneling to underground pipelines by using numerical software, the three dimensional model had been established, the properties of Soil had been obtained. The stiffness of pipeline and the difference will produce the bigger affects for deformation, internal force and stress of the pipelines.

To summarize, the research of the shield tunneling to municipal pipeline has some problems: 1) the problem is two-dimensional, and the material is homogeneous; 2) the affects of pipe-soil interface to pipeline had not been considered.

Based on these reasons, the influences of pipe-soil interface had been considered. The Unit Life and Death Technology of ABAQUS had been used to analyze the dynamic response of pipeline under different working conditions.

\section{Research Status of Soil Deformation Caused by Shield Tunneling in Metro Construction}

Prediction of ground deformation caused by shield construction, Most of them are Peck's formulas and a series of modified Peck's formulas proposed by Peck system. Based on the observation of the shape of the settlement trough on the tunnel surface and a large number of measured data, Peck proposed an empirical formula of ground settlement with normal distribution in tunnel construction stage.

$$
\begin{aligned}
& S(x)=S_{\max } \exp \left(-\frac{x^{2}}{2 i^{2}}\right) \\
& S_{\max }=\frac{V_{\text {loss }}}{\sqrt{2 P i}}
\end{aligned}
$$




$$
V_{\text {loss }}=\eta p R^{2}
$$

Among: $S_{\max }$-the maxium settlement of Horizontal Ground; $S(x)$-Settlement along transverse $x$ distribution; $x$ Horizontal Distance from Settlement Point to Tunnel Center, $\mathrm{m} ; R$-External radius of shield, $\mathrm{m} ; h$-Axis Depth of Tunnel, $\mathrm{m}$; $i$ - Settlement trough width coefficient, that is, the distance between the center of the tunnel and the inflection point of the settlement curve; $v_{\max }$ - Soil loss per unit length of shield tunnel, $\mathrm{m} 3 / \mathrm{m} ; \eta$ - Volume loss rate.

The relation of width coefficient of settlement groove and external radius $R$ of tunnel is as follows:

$$
i=R\left(\frac{h}{2 R}\right)^{n}
$$

Among: $R$-tunnel outer radius (m), $h$ - Tunnel Axis to Ground Depth (m), $n=0.8-1.0$, the softer of the soil, the lager of $n$.

\section{Computation Model and Parameters}

\subsection{Computation Assumption}

The assumptions had been adopted:

(1) Soil is homogeneous, continuous elastic-plastic material, and Ramberg-Osgood model had been adopted.
(2) Uniform Distribution of Soil Layer

(3) The self-weight stress of soil as initial stress

(4) No considering the relative slipping between Shell of Shield Machine and soil surface.

\subsection{Soil Constitutive Model}

Considering nonlinearity of Soil, the Ramberg-Osgood elastic-Plastic model had been used to be constitutive relation. The sketch curve of stress-strain relation is as follows:

$$
E \varepsilon=\sigma+\alpha\left(\frac{|\sigma|}{\sigma_{0}}\right)^{n-1}
$$

Among, $E$ - elastic module, $\varepsilon$-strain, $\sigma$-stress, $\sigma_{0}$-yield stress, $n$-harden parmeter of nonlinear term, $\alpha$-yield offset.

So, we can get hysteretic curve according to Masing rule, so the stress-strain relation curve of re-load is as follows:

$$
\frac{\tau-\tau_{a}}{2}=f\left(\frac{\gamma-\gamma_{a}}{2}\right)
$$

This is the Lower half branch of hysteretic curve, the upper half branch is:

$$
\frac{\tau+\tau_{a}}{2}=f\left(\frac{\gamma+\gamma_{a}}{2}\right)
$$

\subsection{Calculation Parameters}

Table 1. Soil Calculation Parameters.

\begin{tabular}{llllll}
\hline Soil name & $\boldsymbol{E}(\mathbf{M P a})$ & $\boldsymbol{v}$ & $\left.\rho \mathbf{( k g} / \mathbf{m}^{\mathbf{3}}\right)$ & Cohesion force $\mathbf{c}(\mathbf{k P a})$ & Internal frictional angle $\phi(\mathbf{d e g r e e})$ \\
\hline Soil 1 & 4.76 & 0.36 & 1781 & 12 & 21.8 \\
Soil 2 & 6.38 & 0.39 & 1883 & 23.4 & 18.3 \\
Soil 3 & 9.55 & 0.37 & 1973 & 12.6 & 29.3 \\
Soil 4 & 12.50 & 0.34 & 2000 & 38.3 & 21.4 \\
\hline
\end{tabular}

Table 2. Pipe diameter.

\begin{tabular}{llll}
\hline Pipe diameter $(m)$ & 1.25 & 1.0 & 0.75 \\
\hline
\end{tabular}

Table 3. Pipe parameters.

\begin{tabular}{llll}
\hline Material & $\boldsymbol{E}(\boldsymbol{G P a})$ & $\boldsymbol{v}$ & $\rho\left(\mathbf{k g} / \mathbf{m}^{\mathbf{3}}\right)$ \\
\hline Steel pipe & 210 & 0.3 & 7850 \\
Concrete pipe & 25 & 0.2 & 2500 \\
\hline
\end{tabular}

\section{Calculation Results Analysis}

Shield tunneling subway is a complicate process. In order to analyze the regular pattern, we can assume that other affect parameters did not change, and analyze the regular law of certain parameter to pipeline.

\subsection{The Affect of Soil on Pipeline Displacement}

From the above figures, We can find that the underground pipline's vertical displacement are similar to surface settlement trough curve, and also with the increase of soil stiffnes, the vertical displacement of pipeline is getting smaller and smaller. The biggest pipeline displacement of these four soil layer is $41.23,33.24,26.76,23.43 \mathrm{~mm}$, the displacement of soil layer1 is bigger, is not safe, Which can decrease pipeline vertical by grouting reinforcement and other measures, so we can find that the effect of different soil texture on the linear behavior of pipe is significant. So during the construction process, we should pay more attention to the change of soil texture change. 


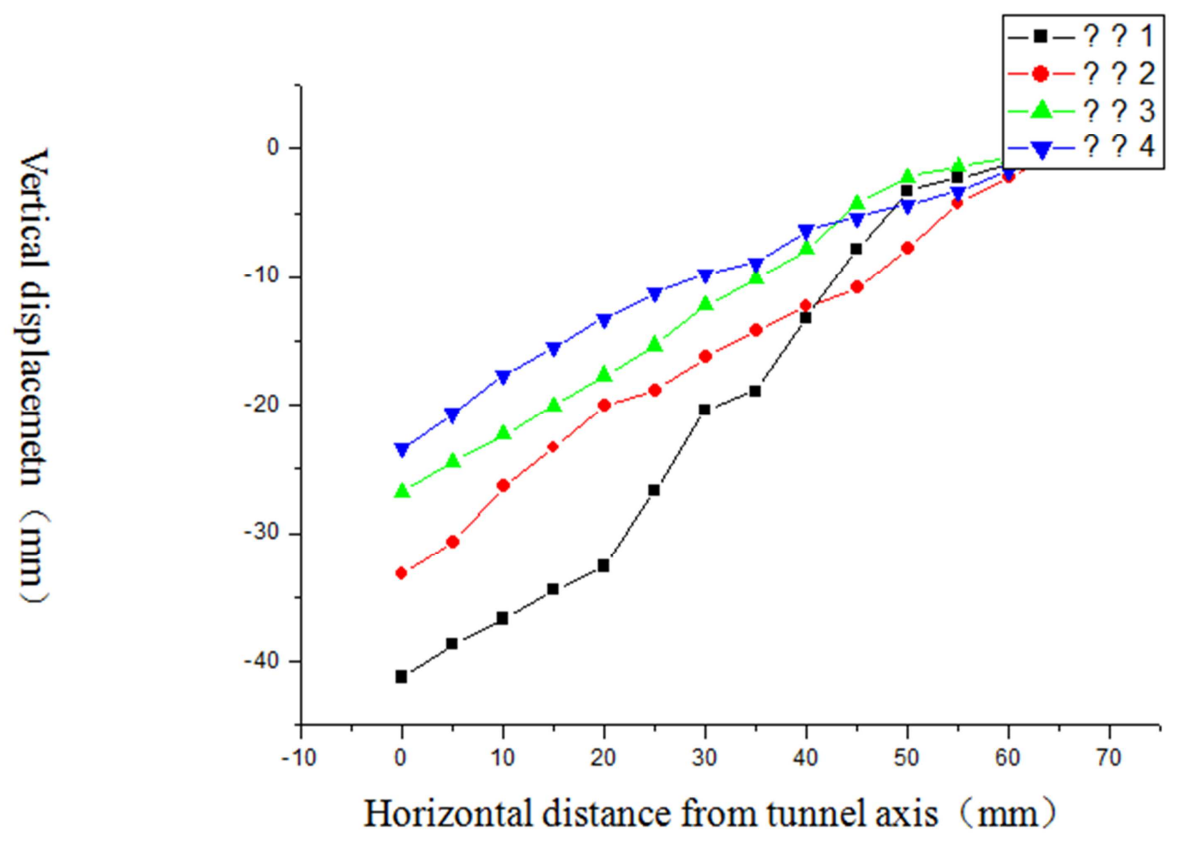

Figure 1. The relation of different soil and pipe's vertical displacement.

\subsection{The Affect of Pipe Diameter on Pipeline Displacement}

When the reinforced concrete pipe diameter is $1.25 \mathrm{~m}, 1.0$ $\mathrm{m}$ and $0.75 \mathrm{~m}$, pipe wall is $125 \mathrm{~mm}, 100 \mathrm{~mm}$ and $75 \mathrm{~mm}$, the relationship between pipe diameter's vertical displacement and pipe diameter is as follows:

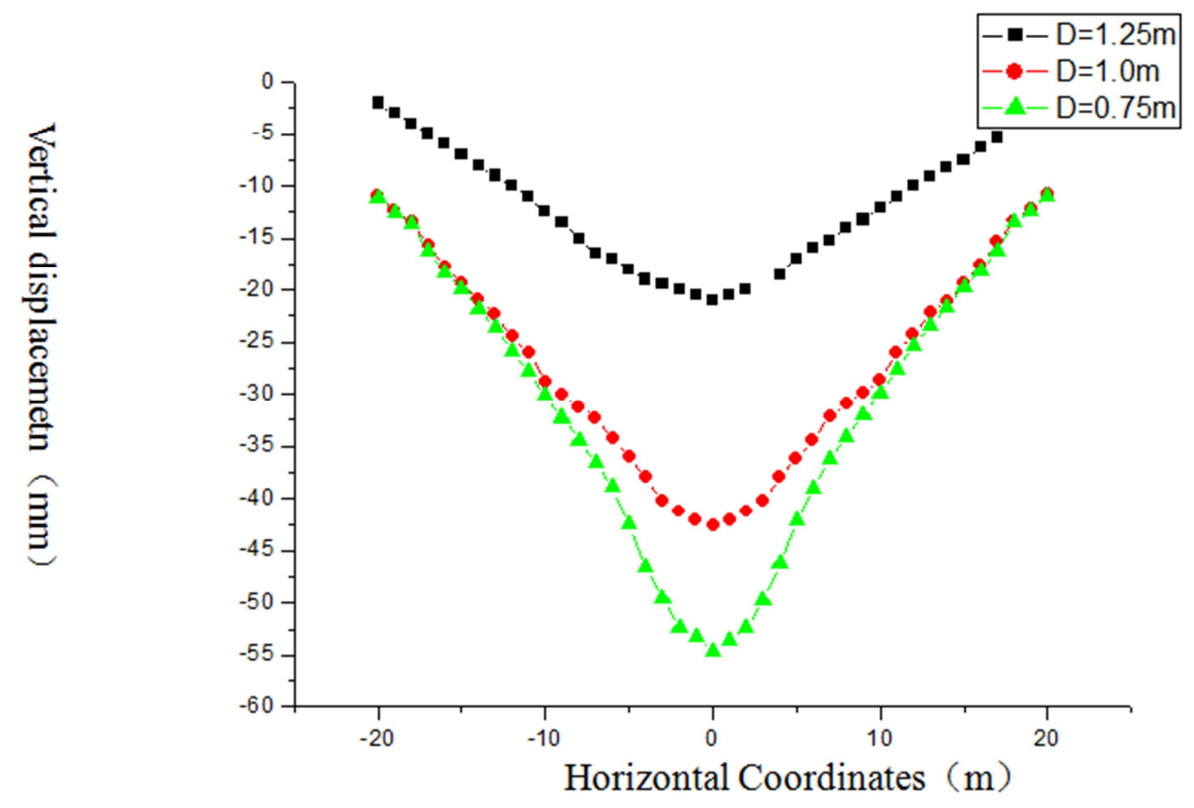

Figure 2. The relation of different pipe diameter and pipe's vertical displacement.

From the above figure, the vertical displacement of pipeline is symmetrical distribution, and getting smaller and smaller with the increase of pipe diameter. This is because that the pipe diameter is bigger, also the area and the stiffness, so the resistance to deformation is bigger, and the affect of shield tunneling is smaller. So the pipeline was arranged, under the same other conditions, pipelines with larger diameter should be selected as far as possible, this makes it safe.

\subsection{The Relation Between Cutter Head Propulsion and Pipeline}

The total horizontal propulsion of shield was $0.1 \sim 0.3 \mathrm{MPa}$ according to the soil and water pressure in front of shield tunnel, and over-excavation, under-excavation, shield head-up, curve advance and deviation rectification and so on during shield excavation. 


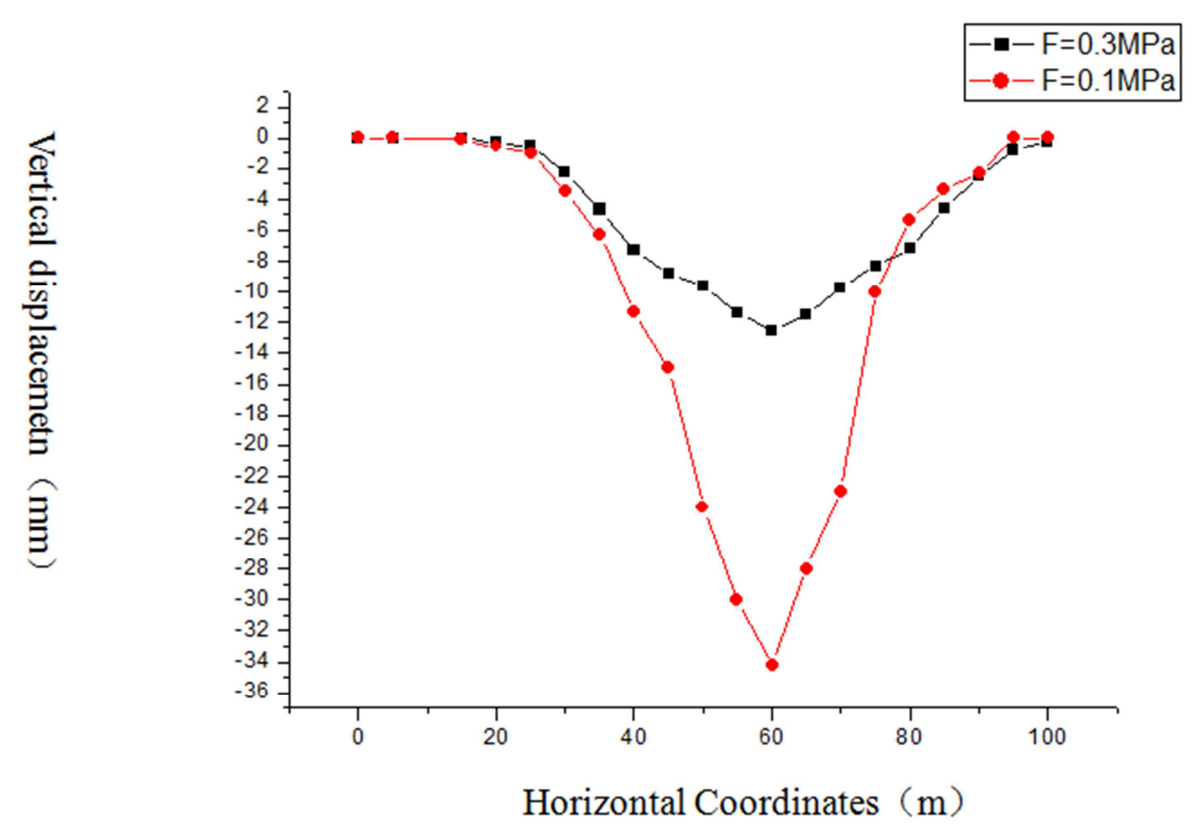

Figure 3. The relation between cutter head propulsion and pipeline vertical displacement.

From the figure 3, we can find that with the increase of getting smaller, and reach to the maximum value. This is due cutter head propulsion, the pipe vertical displacement is to the change of soil and water pressure during construction.

\subsection{The Relation Between Pipe's Elastic Module and Vertical Displacement}

By changing the value of pipeline's elastic module, the results are as follows:

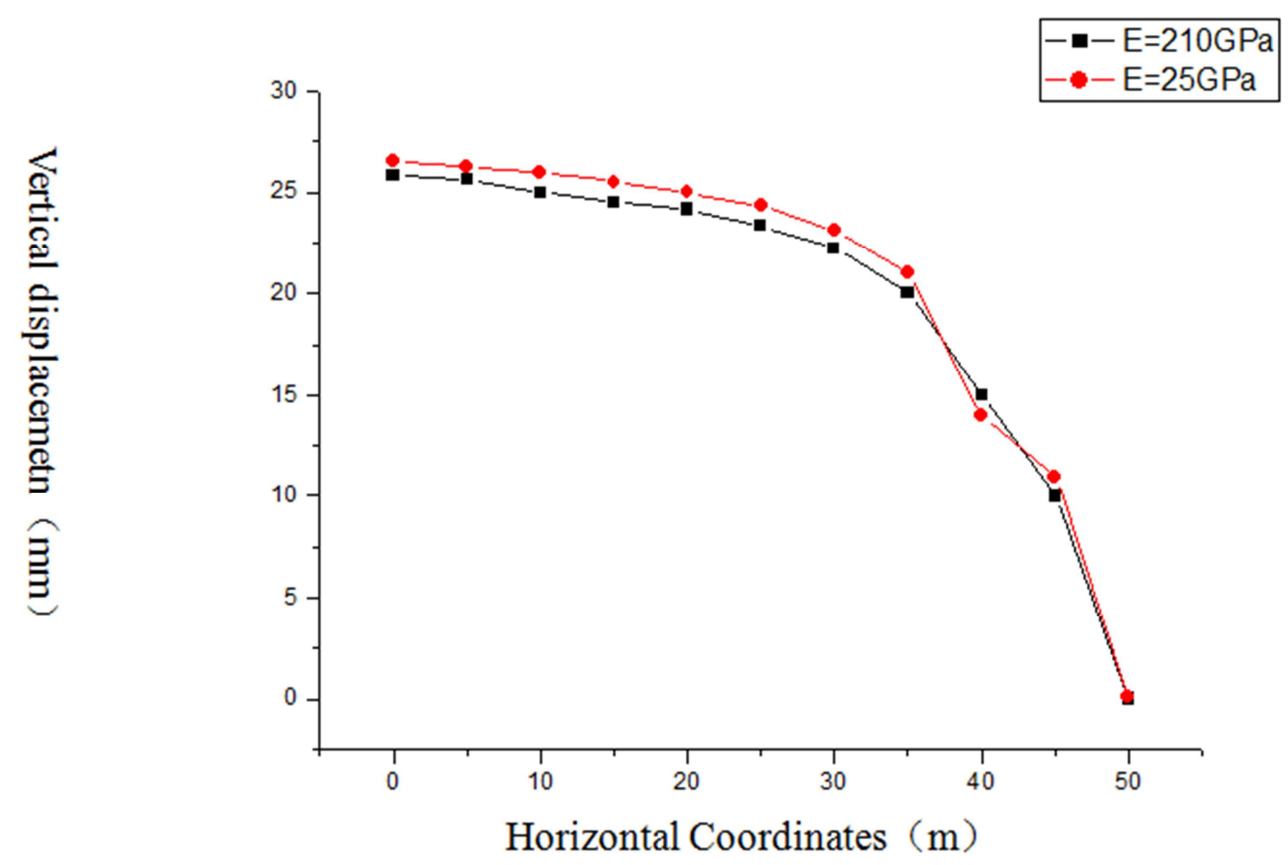

Figure 4. The relation between pipe's elastic module and vertical displacement.

From the above figure, we can find that the settlement of pipeline increases slightly with the decrease of stiffness, but the range of change is not very large. Therefore, it is not necessary to consider the influence of elastic modulus of pipeline in construction.

\subsection{The Influence of Distance Between Pipeline and Tunnel}

When the parameters of other working conditions remain unchanged, the burial depth is simulated at $2.6 \mathrm{~m}$ and $2.4 \mathrm{~m}$, Pipeline displacement due to tunnel excavation is as follows: 


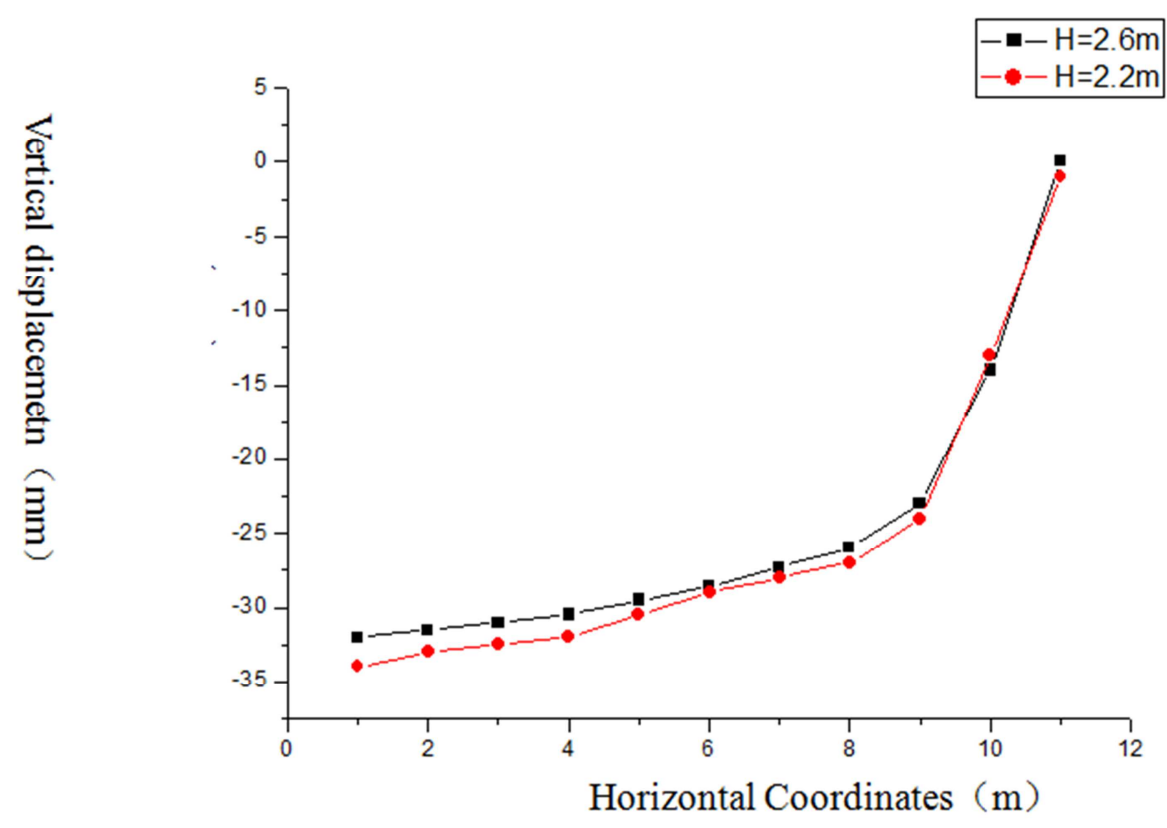

Figure 5. The relationship between vertical displacement and burial depth of pipeline.

From the above figure, we can find that with the increase of pipeline distance from tunnel depth, the influence of pipeline excavation becomes smaller and smaller. When the buried depth of pipeline is $H=2.6 \mathrm{~m}$, the maximum vertical displacement of pipeline is $32 \mathrm{~mm}$, but when the buried depth of pipeline is $H=2.4 \mathrm{~m}$, the maximum vertical displacement of pipeline is $36 \mathrm{~mm}$. With the increase of the distance between pipeline and tunnel, the greater the buried depth, the smaller the displacement of pipeline, that is, pipelines are less and less affected by tunnel excavation. Therefore, if other conditions remain unchanged, the pipeline will be buried as deep as possible, and the degree of interference will decrease.

\subsection{Effect of Grouting Pressure on Pipeline Displacement}

During shield driving, grouting pressure, grouting volume and grouting strength will affect underground pipelines. This paper mainly considers the influence of grouting pressure on underground pipelines under the condition of constant grouting volume.

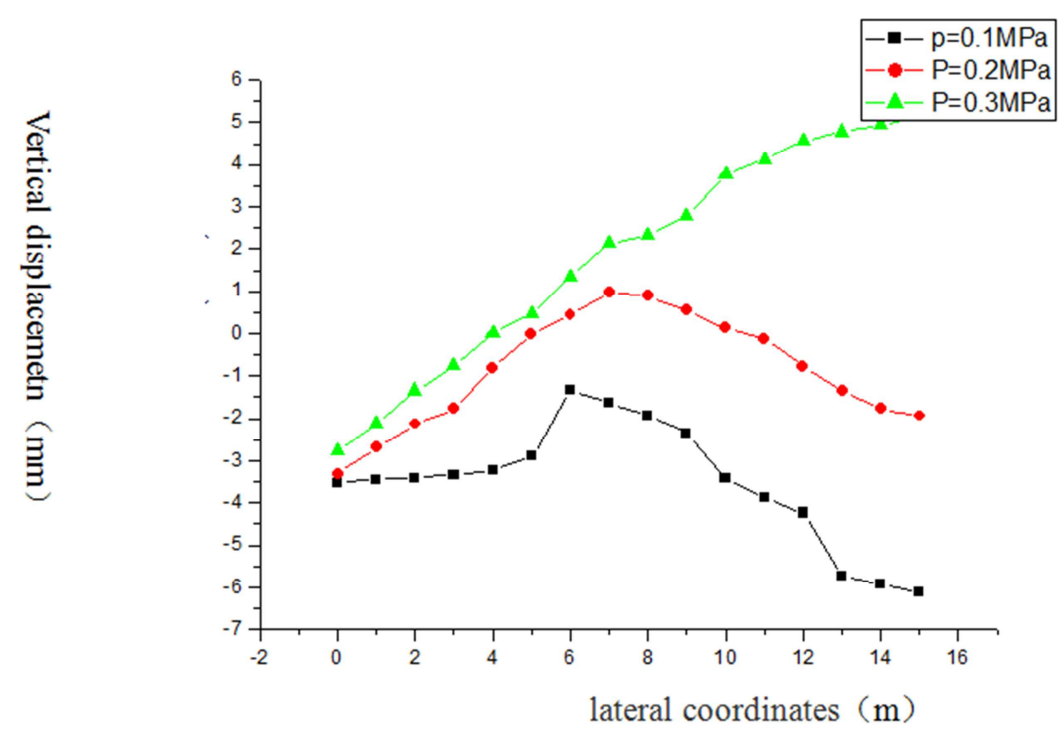

Figure 6. the relationship between grouting pressure and vertical displacement of pipeline.

In theory, grouting pressure $P$ should be slightly larger than surrounding water and soil pressure $P_{0}$ in order to effectively fill annular voids. The grouting pressure mainly affects the vertical displacement of underground pipelines, in this paper, the grouting pressure is $0.1,0.2 \mathrm{MPa}$ and $0.3 \mathrm{MPa}$. It can be seen from the figure that when the grouting pressure is 0.2 $\mathrm{MPa}$, the vertical displacement of the pipeline is the smallest. In this case, the effect on pipeline is minimal. The results are shown in Figure 6. 


\section{Conclusion}

It can be seen from the above simulation results that tunnel burial depth, cutter head thrust, pipe diameter and buried depth have great influence on pipeline displacement. According to the importance of pipeline, on the premise of guaranteeing normal construction, the main construction parameters are adjusted and controlled to minimize pipeline displacement.

The numerical calculation results obtained from this paper can provide beneficial theoretical basis for displacement prediction of adjacent underground pipelines during shield tunneling. By estimating the time and place of maximum displacement, take corresponding protective measures beforehand to ensure the smooth progress of the whole construction.

Driving surface thrust is side pressure value, 0.5 times and 1.5 times caused by self-weight. It is found that when the thrust is small, the vertical displacement of the pipeline is larger than that of the large thrust.

The dynamic analysis of shield tunneling construction of Metro municipal pipelines is an important link to ensure the safety of urban metro construction. According to the importance of pipelines, the main construction parameters can be adjusted and controlled under the condition of normal construction, controlling favorable factors and eliminating unfavorable factors, minimizing pipeline displacement and dynamic response, so that the construction is safer and more effective. Therefore, the influence of these unfavorable factors should be controlled during construction.

\section{Acknowledgements}

This paper is supported by Special Funds for Fundamental Research Business Fees of Municipal Universities of Beijing University of Civil Engineering and Architectural. The Fund number is $\mathrm{X} 18248$.

\section{References}

[1] Ma lin, Analysis of Impact of Shield Tunnel Excavation on Pipeline and Surface, Journal of Shi JiaZhuang Tiedao University, 28 (2), 2015. 6.

[2] Fan xiaowei, Wangtao, Finite Element Analysis on Influence of of Shield Tunnel to Underground Pipelines, Tunnel Construction, 30 (6), 2010.
[3] Jiang xinliang, Cuiyi etc, Measurement and Dynamic Simulation of Ground Deformation in Shield Tunneling Construction of Tianjin Metro, Railway Transaction, 2005, 27 (1).

[4] Zhang zhiqiang, He chuan etc, Three-dimensional Finite Element Simulation Analysis of Shield Tunneling Construction in Nanjing Metro, Railway Transaction, 2005, 27 (1).

[5] Zhang fengxiang, Zhu hehua etc. Shiel tunnel, Beijing: People's transportation press, 2004.

[6] Zhang haibo, Numerical Simulation of the environmental effects of Shield-Tunnel Construction in Subway Tunnel [D], Hehai University, 2005.

[7] Xiao wanghui etc, Numerical simulation of the influence of Shield Tunnel Construction on underground pipeline, Construction Technology, 37 (3), 2008. 7.

[8] Bi jihong, Liuwei, Jiangzhifeng etc, Analysis of the influence of tunnel excavation on Underground Pipeline, Rock and Soil Mechanics, 27 (8), 2006. 8.

[9] Sun haixia, Zhao wen etc, Monitoring and numerical simulation of subsidence of underground pipeline in Shield Tunneling, Journal of Shenyang University of Technology, 32 (4), 2010. 8.

[10] Wei gang, Wangchen, Cui chenghong, Review of model test on influence of shield tunnel construction on adjacent underground pipeline, Low Temperature Architecture Technology, 40 (9), 2018. 9.

[11] Wang wanting, huang shan, etc. Influence of Shield Tunneling Passing beneath Underground Pipeline and the Control Technology, Construction Technoloy. (6), 2018.

[12] WANG Zhongchang, GUO Xinping, WANG Chuan, TANG Jing, Influence Analysis of Subway Shield Tunnel Construction on Adjacent Pipeline, Journal of DaLian JiaoTong University, 39 (4), 2018.

[13] Ma jing, Impact Analysis of Subway Shield Tunneling under Drainage Pipelines, Track Traffic \& Underground Engineering, 37 (3), 2019.

[14] $\mathrm{Wu}$ hao, Study on the influence of metro shield tunnel construction on Urban Underground Pipeline, Technology wind, 2018. 12

[15] Huang Xiaokang, Wang weidong, etc. Model test study of underground pipeline affected by metro shield tunneling, Journal of He Fei University of Technoloy, 41 (6), 2018.

[16] Zhang Hongge, Study on the Influence of Shield Tunneling on Deformation of Underground Pipeline, Western Transportation Science and Technology, 2019. 4. 